\title{
PREMI TUNGGAL ASURANSI JIWA SEUMUR HIDUP UNIT LINK DENGAN GARANSI MINIMUM DAN NILAI CAP MENGGUNAKAN METODE POINT TO POINT
}

\author{
Ni Luh Juliantari ${ }^{1 \S}$, I Wayan Sumarjaya ${ }^{2}$, I Nyoman Widana ${ }^{3}$ \\ ${ }^{1}$ Jurusan Matematika, FMIPA - UniversitasUdayana [Email: juliantari80@ gmail.com] \\ ${ }^{2}$ Jurusan Matematika, FMIPA - UniversitasUdayana [Email: sumarjaya @ gmail.com] \\ ${ }^{3}$ Jurusan Matematika, FMIPA - UniversitasUdayana [Email: nwidana @ yahoo.com] \\ ${ }^{\S}$ Corresponding Author
}

\begin{abstract}
Unit-linked whole life insurance is an insurance that combines traditional whole life insurance with modern insurance unit-links which provide both protection and investment. One of indexing method for calculating premium of unit-linked insurance is point to point method. The data used in this study was the closing price of PT. Astra Agro Lestari, Indonesia Tbk and The mortality table used in this research is Indonesia's Mortalita Table III Men. It was obtained that the net single premium for whole life insurance unit-linked for the insured aged 45 years is amounted to Rp350.324,-.
\end{abstract}

Keywords: Point to Point method, Unit-Linked, Whole Life Insurance

\section{PENDAHULUAN}

Life insurance atau asuransi jiwa digunakan untuk menjamin risiko kematian seseorang, baik yang disebabkan penyakit, kecelakaan, atau bencana alam. Asuransi jiwa merupakan usaha kerjasama dari sejumlah orang yang sepakat memikul kesulitan keuangan bila terjadi musibah terhadap salah seorang anggota (Sembiring, 1986). Asuransi jiwa dibagi menjadi dua yaitu asuransi jiwa tradisional dan asuransi jiwa modern. Asuransi jiwa tradisional terdiri dari asuransi jiwa berjangka, asuransi jiwa seumur hidup, dan asuransi jiwa dwiguna (endowment). Sedangkan asuransi modern terdiri dari asuransi jiwa universal, unitzed with profit, dan asuransi jiwa unit link (Dickson dkk. 2009).

Asuransi jiwa seumur hidup ialah serangkaian pembayaran (besarnya pembayaran berkala boleh berubah) yang dilakukan selama seseorang tertentu masih hidup, pembayaran hanya dilakukan bila pada waktu pembayaran itu jatuh orang tersebut masih hidup (Sembiring, 1986). Asuransi jiwa seumur hidup memiliki kelebihan memberikan manfaat saat tertanggung meninggal dunia. Manfaat diberikan kepada ahli waris atau penerima manfaat (Karvof, 2010). Pada asuransi jiwa seumur hidup, nilai aset yang diasuransikan dianggap tetap setiap waktu sehingga manfaat yang diperoleh bernilai sama. Sedangkan pada kenyataannya pendapatan seseorang dapat berubah setiap saat.

Sebagian masyarakat kini lebih memilih untuk menginvestasikan uangnya karena dianggap lebih menguntungkan dibandingkan mengikuti asuransi jiwa tradisional. Investasi dapat dilakukan pada aset finansial (deposito, saham atau obligasi) (Tandelilin, 2010). Demi meningkatkan minat masyarakat untuk mengikuti asuransi maka dikembangkan asuransi unit link. Menurut Sartika dan Adinugraha (2013) produk unit link merupakan produk yang paling banyak diminati oleh masyarakat Indonesia. Karena asuransi unit link mengandung unsur investasi, untuk menghitung manfaat yang diperoleh tertanggung dapat digunakan metode pengindeksan. Ada tiga metode pengindeksan yang dapat digunakan 
untuk menghitung manfaat asuransi unit link yaitu point to point, annual ratchet, dan high water mark (Hardy, 2003).

Pada penelitian ini digunakan metode point-to-point untuk menghitung manfaat asuransi unit link. Metode point to point memiliki kelebihan dibandingkan dengan dua metode yang lain, yaitu melindungi nasabah terhadap penurunan harga saham di tengah jalan. Metode point to point merupakan metode pengindeksan manfaat yang paling sederhana dibandingkan dua metode lainnya. Hal ini dikarenakan point to point mengabaikan adanya fluktuasi harga saham antara awal sampai akhir kontrak, manfaat diperoleh dari hasil selisih harga saham saat jatuh tempo dengan harga saham saat kontrak polis (Hardy, 2003)

Manfaat yang diterima pada unit link berdasarkan investasi (harga saham), yang berarti inflasi memengaruhi besarnya manfaat yang diterima tertanggung. Saat harga saham tinggi manfaat yang diterima tertanggung pun tinggi, sehingga penanggung akan mengalami kerugian. Begitu juga sebaliknya, saat harga saham turun maka tertanggung akan mengalami kerugian. Oleh karena itu agar kontrak saling menguntungkan penanggung membatasi manfaat yang akan diterima tertanggung dengan nilai minimum (garansi minimum) dan nilai maksimum (cap). Pada akhir kontrak saat harga saham tinggi tertanggung akan menerima manfaat sebesar nilai cap dan saat harga saham rendah tertanggung akan menerima manfaat sebesar garansi minimum. Berdasarkan latar belakang, pada penelitian ini penulis akan menghitung premi menggunakan waktu diskret serta menurunkan ulang premi tunggal bersih asuransi jiwa seumur hidup unit-link menggunakan metode point to point dengan batasan nilai cap dan garansi minimum, karena premi tunggal dari asuransi jiwa seumur hidup berbeda dengan asuransi jiwa dwiguna sehingga formula dan hasil hitung premi yang akan diperoleh pun berbeda.

Asuransi jiwa seumur hidup ialah serangkaian pembayaran premi yang dilakukan selama seseorang tertentu masih hidup saat waktu pembayaran. Pembayaran premi dapat dilakukan sekaligus (premi tunggal) atau dengan jangka waktu tertentu. Pada asuransi jiwa seumur hidup manfaat pasti akan dibayarkan tanpa memperdulikan waktu tertanggung meninggal (Sembiring, 1986). Menurut Bowers dkk., (1997) premi tunggal asuransi jiwa seumur hidup dinyatakan sebagai:

$$
A_{x}=\sum_{k=0}^{\infty} v^{k+1}{ }_{k} p_{x} q_{x+k} .
$$

Asuransi jiwa unit link merupakan asuransi jiwa modern dengan pembayaran manfaat dilakukan pada akhir kontrak polis. Menurut Muyasarah (2010) asuransi jiwa unit link memiliki karakteristik sebagai berikut :

1. Asuransi unit link dapat digunakan sebagai alat tabungan dan proteksi. Proteksi dapat berbentuk proteksi meninggal, cacat tetap total, dan meninggal karena kecelakaan.

2. Pada umumnya asuransi unit link mempunyai pilihan jenis investasi yang beragam mulai dari konservatif, moderat, dan agresif.

3. Biaya proteksi umumnya terpenuhi dengan membebankan biaya tersebut sesuai dengan usia dan besarnya proteksi. Biaya ini dibebankan dengan melakukan pengurangan jumlah unit dari dana yang tersedia kecuali untuk premi tunggal.

4. Asuransi unit link bersifat transparansi sehingga pemegang polis dapat secara leluasa memantau perkembangan harga saham setiap saat melalui media cetak atau link website dari perusahaan asuransi yang diikuti.

5. Setiap pemegang polis mendapatkan laporan besar premi yang harus dibayarkan di tahun pertama serta hasil investasi yang diperoleh selama satu tahun berjalan.

6. Asuransi unit link bersifat fleksibel. Beberapa ciri fleksibilitas asuransi unit link adalah sebagai berikut:

a. Premi dapat dikurangi atau ditinggalkan selama nilai tunai dari investasi yang diikuti masih mencukupi untuk membayar premi tersebut. Tingkat proteksi juga dapat diubah sesuai dengan keinginan pemegang 
polis tentunya harus sesuai dengan persyaratan yang berlaku.

b. Pengambilan nilai tunai dari investasi yang dapat dilakukan kapan saja. Penambahan premi untuk menambah jumlah investasi yang ditempatkan dapat juga dilakukan dari waktu ke waktu.

Investasi merupakan komitmen untuk menanamkan sejumlah dana pada saat ini dengan tujuan memperoleh keuntungan di masa datang. Investasi dapat dilakukan pada deposito, saham atau obligasi (aset finansial) (Husnan, 2015). Menurut Elliott \& Kopp (2005) aset finansial dapat dibagi menjadi dua yaitu aset dengan risiko (risky asset) dan aset bebas risiko (riskless asset). Pada penelitian ini investasi akan dilakukan pada investasi agresif yaitu asset dengan resiko saham. Model pergerakan harga saham pada waktu $t$ adalah

$$
S_{t}=S_{0} e^{\sigma Z \sqrt{t}+\left(r-\frac{1}{2} \sigma^{2}\right) t} .
$$

dengan $Z$ merupakan variabel acak berdistribusi normal standar dan $r$ merupakan tingkat suku bunga bebas risiko.

Menurut Husnan (2015) return saham adalah tingkat keuntungan saham. Return saham pada waktu $t$ dapat dihitung sebagai berikut (Elliott \& Kopp, 2005):

$$
R_{t}=\ln \left(\frac{S_{t}}{S_{t-1}}\right)
$$

Menurut Husnan (2015) resiko merupakan kemungkinan tingkat keuntungan yang diperoleh menyimpang dari tingkat keuntungan yang diharapkan. Tingkat keuntungan yang diharapkan dari investasi dapat dihitung sebagai berikut:

$$
\bar{R}=\frac{\sum_{t=1}^{n} R_{t}}{n} .
$$

Tingkat risiko pada suatu saham dapat dihitung sebagai berikut :

$$
\sigma=\sqrt{(n+1) \frac{\sum_{t=1}^{n}\left[R_{t}-\bar{R}\right]^{2}}{(n-1)}} .
$$

Secara sistematis, perhitungan hasil investasi menggunakan metode point to point dinyatakan sebagai berikut (Gaillardetz \& Lakhmiri, 2011):

$$
H_{t}=\frac{S_{t}-S_{0}}{S_{0}}
$$

Pengaruh inflasi dapat mengakibatkan kerugian pada tertanggung, yang akan terjadi saat harga saham turun. Sehingga pihak asuransi memberikan garansi minimum pada tertanggung. Garansi minimum merupakan nilai minimum dari manfaat yang diberikan oleh pihak asuransi kepada pemegang polis pada saat harga saham turun. Fungsi garansi minimum dapat dinyatakan sebagai berikut (Gaillardetz \& Lakhmiri, 2011):

$$
G_{t}=\beta(1+g)^{t} .
$$

Selain itu inflasi juga dapat mengakibatkan pihak asuransi merugi, yang terjadi saat harga pasar saham tinggi. Sehingga untuk mengatasi permasalah ini perusahaan asuransi harus memberikan batasan nilai maksimum (cap) dari manfaat yang diterima pemegang polis. Fungsi cap maksimum dapat dinyatakan sebagai berikut (Gaillardetz \& Lakhmiri, 2011):

$$
C_{t}=(1+c)^{t}
$$

Nilai investasi dari struktur manfaat $b_{t}=$ $\max \left\{\min \left[1+\alpha H_{t},(1+c)^{t}\right], \beta(1+g)^{t}\right\}$ yang akan diperoleh pada waktu $t$ adalah sebagai berikut:

$$
\begin{aligned}
\Pi(t)= & \alpha(\Phi(\delta)-\Phi(\kappa))+e^{-r t}\left[\beta(1+g)^{t}\right. \\
& -\left\{\beta(1+g)^{t}-(1-\alpha)\right\} \Phi(\xi) \\
& \left.+\left\{(1+c)^{t}-(1-\alpha)\right\} \Phi(v)\right]
\end{aligned}
$$

dengan $\Phi$ merupakan fungsi distribusi kumulatif normal standar,

$$
\begin{array}{r}
\delta=\sigma \sqrt{t}+\frac{\left(r-\frac{1}{2} \sigma^{2}\right) t}{\sigma \sqrt{t}} \\
\frac{-\ln \frac{\beta(1+g)^{t}-(1-\alpha)}{\alpha}}{\sigma \sqrt{t}} \\
\xi=\delta-\sigma \sqrt{t} \\
\kappa=\sigma \sqrt{t}+\frac{\left(r-\frac{1}{2} \sigma^{2}\right) t}{\sigma \sqrt{t}} \\
\frac{-\ln \frac{(1+c)^{t}-(1-\alpha)}{\alpha}}{\sigma \sqrt{t}} \\
v=\kappa-\sigma \sqrt{t}
\end{array}
$$




\section{METODE PENELITIAN}

Data yang digunakan pada penelitian ini merupakan data sekunder yang berupa:

1. Harga penutupan saham untuk studi kasus pada PT. Astra Agro Lestari,Tbk dalam rentang waktu 5 Januari 2015 sampai 26 Desember 2015 yang diperoleh dari Yahoo Finance.

2. Suku bunga dan data tertanggung berusia 45 tahun yang diperoleh dari tabel mortalita.

Langkah-langkah yang akan dilakukan untuk merumuskan dan menghitung premi tunggal asuransi jiwa seumur hidup unit link dengan garansi minimum dan nilai cap menggunakan metode point to point yaitu :

1. Menghitung harga saham berpola gerak Brown geometrik dengan asumsi probabilitas risiko netral.

2. Menghitung fungsi densitas probabilitas variabel acak harga saham $X$.

3. Menentukan nilai investasi dari struktur manfaat menggunakan metode point-topoint dengan batasan garansi minimum dan nilai cap.

4. Merumuskan premi tunggal bersih asuransi jiwa seumur hidup unit link.

5. Menghitung premi tunggal bersih asuransi jiwa seumur hidup unit link untuk tertanggung berusia 45 tahun.

\section{HASIL DAN PEMBAHASAAN}

\section{Harga Saham dengan Asumsi Probabilitas Resiko Netral}

Pada pembahasan ini pertama akan dihitung return dan volatilitas dari harga penutupan saham PT. Astra Agro Lestari,Tbk (5 Januari 2015 sampai 26 Desember 2015) dengan asumsi probabilitas resiko netral. Berdasarkan hasil hitung menggunakan persamaan (3) diperoleh nilai return saham sebagai berikut:
Tabel 1. Perhitungan Return

\begin{tabular}{|c|c|c|}
\hline$t$ & $S_{t}$ & $R_{t}$ \\
\hline 0 & 24675 & - \\
\hline 1 & 24300 & -0.01531 \\
\hline 2 & 24700 & 0.01633 \\
\hline 3 & 25225 & 0.02103 \\
\hline 4 & 25975 & 0.02930 \\
\hline 5 & 25800 & -0.00676 \\
\hline 6 & 25900 & 0.00387 \\
\hline 7 & 24900 & -0.03938 \\
\hline 8 & 24950 & 0.00201 \\
\hline 9 & 24725 & -0.00906 \\
\hline 10 & 24675 & -0.01531 \\
\hline
\end{tabular}

Sebelum menghitung nilai volatilitas saham terlebih dahulu akan dihitung tingkat keuntungan yang diharapkan dari investasi menggunakan persamaan (4) diperoleh:

$$
\begin{aligned}
\bar{R} & =\frac{-0,46495}{255} \\
& =-0,00182
\end{aligned}
$$

dan berdasarkan persamaan (5) dapat dihitung nilai volatilitas saham sebagai berikut:

$$
\begin{aligned}
\sigma & =\sqrt{256\left(\frac{0,21830}{254}\right)} \\
& =0,469057
\end{aligned}
$$

\section{Fungsi Densitas Probabilitas Variabel Acak Harga Saham X}

Berdasarkan persamaan (6) sebelum menghitung fungsi distribusi kumulatif normal standar perlu dihitung terlebih dahulu nilai garansi minimum dan nilai cap. Garansi minimum $\left(G_{k}\right)$ dapat dihitung menggunakan persamaan (7) dengan garansi minimum dari awal premi $(\beta)=0,9$ dan suku bunga garansi $(g)=0,05$ dan nilai cap dapat dihitung menggunakan persamaan (8) dengan suku bunga cap $(c)=0,3$ sehingga diperoleh: 
Tabel 2. Perhitungan Garansi Minimum dan Nilai Cap

\begin{tabular}{|c|c|c|}
\hline$k$ & $G_{k}$ & $C_{k}$ \\
\hline 1 & 0,945000 & 1,30000000000 \\
\hline 2 & 0,992250 & 1,69000000000 \\
\hline 3 & 1,041863 & 2,19700000000 \\
\hline 4 & 1,093956 & 2,85610000000 \\
\hline 5 & 1,148653 & 3,71293000000 \\
\hline 6 & 1,206086 & 4,82680900000 \\
\hline 7 & 1,266390 & 6,27485170000 \\
\hline 8 & 1,329710 & 8,15730721000 \\
\hline 9 & 1,396195 & 10,60449937300 \\
\hline 10 & 1,466005 & 13,78584918490 \\
\hline
\end{tabular}

Selanjutnya akan dihitung fungsi distribusi kumulatif normal standar $(\Phi)$ pada persamaan (9) dengan partisipan $(\alpha)=0.7$ dan suku bunga $(r)=0,064$ sehingga diperoleh:

Tabel 3. Perhitungan Fungsi Distribusi Kumulatif Normal Standar

\begin{tabular}{|c|c|c|c|}
\hline$\Phi d_{1}$ & $\Phi d_{2}$ & $\Phi d_{3}$ & $\Phi d_{4}$ \\
\hline 0.952214 & 0.747521 & 0.999938 & 0.997732 \\
\hline 0.968928 & 0.674023 & 1 & 0.999998 \\
\hline 0.981572 & 0.638819 & 1 & 1 \\
\hline 0.98926 & 0.617699 & 1 & 1 \\
\hline 0.993772 & 0.603689 & 1 & 0.999974 \\
\hline 0.996396 & 0.593899 & 1 & 0.999342 \\
\hline 0.997917 & 0.586872 & 1 & 0.997285 \\
\hline 0.998797 & 0.581777 & 1 & 0.994315 \\
\hline 0.999306 & 0.578096 & 1 & 0.991323 \\
\hline 0.9996 & 0.575489 & 1 & 0.988806 \\
\hline
\end{tabular}

\section{Nilai Investasi dari Struktur Manfaat dengan Metode Point-to-Point}

Berdasarkan hasil hitung sebelumnya akan dihitung besar nilai investasi yang akan diperoleh tertanggung menggunakan persamaan (9) sehingga diperoleh:

Tabel 4. Perhitungan Nilai Investasi

\begin{tabular}{|c|c|}
\hline$k$ & $\Pi(k)$ \\
\hline 1 & 0.775099055 \\
\hline 2 & 0.154728297 \\
\hline 3 & 0.02815935 \\
\hline 4 & 0.535652789 \\
\hline 5 & 0.167061994 \\
\hline 6 & -0.00252281 \\
\hline 7 & -0.00145833 \\
\hline 8 & 0.970780751 \\
\hline 9 & 1.019396484 \\
\hline 10 & 1.063412857 \\
\hline
\end{tabular}

\section{Premi Tunggal Bersih Asuransi Jiwa Seumur Hidup Unit Link}

Pada asuransi unit link premi yang dibayarkan oleh tertanggung akan diinvestasikan, sehingga nilai sekarang dari asuransi seumur hidup dapat dikonversi menjadi nilai investasi asuransi jiwa seumur hidup unit link. Jadi berdasarkan nilai investasi pada persamaan (9), diperoleh penyelesaian premi tunggal bersih asuransi jiwa seumur hidup unit link sebagai berikut:

$$
\begin{aligned}
P= & \sum_{k=1}^{\infty} U(k) e^{-r k}\left[\beta(1+g)^{k}\right. \\
& -\left\{\beta(1+g)^{k}-(1-\alpha)\right\} \Phi(\xi) \\
& \left.+\left\{(1+c)^{k}-(1-\alpha)\right\} \Phi(v)\right] \\
& +\alpha(\Phi(\delta)-\Phi(\kappa))
\end{aligned}
$$

dengan $\Phi$ merupakan fungsi distribusi kumulatif normal standar,

$$
\begin{aligned}
& U(k)={ }_{k-1} p_{x} q_{x+k-1}, \quad k=1,2, \ldots \\
& \delta=\sigma \sqrt{k}+\frac{\left(r-\frac{1}{2} \sigma^{2}\right) k}{\sigma \sqrt{k}} \\
& \frac{-\ln \frac{\beta(1+g)^{k}-(1-\alpha)}{\alpha}}{\sigma \sqrt{k}} \\
& \xi=\delta-\sigma \sqrt{k} \\
& \kappa=\sigma \sqrt{k}+\frac{\left(r-\frac{1}{2} \sigma^{2}\right) k}{\sigma \sqrt{k}} \\
& \frac{-\ln \frac{(1+c)^{k}-(1-\alpha)}{\alpha}}{\sigma \sqrt{k}} \\
& v=\kappa-\sigma \sqrt{k}
\end{aligned}
$$

\section{Menghitung Premi Tunggal Bersih Asuransi Jiwa Seumur Hidup Unit Link}

Pada premi tunggal bersih asuransi jiwa seumur hidup unit link diasumsikan log return saham berdistribusi normal. Pada penelitian ini dihitung premi tunggal bersih asuransi jiwa seumur hidup unit link untuk seorang tertanggung berusia 45 tahun yang berinvestasi pada saham PT. Astra Agro Lestari,Tbk tahun 2015 yang diperoleh dari Yahoo Finance dengan:

$$
\begin{aligned}
& S_{0}=\text { Rp. 24.675, }- \text { per lembar } \\
& a \quad=1
\end{aligned}
$$




$$
\begin{aligned}
\sigma & & =0.469057 \\
r & & =6,4 \% \\
\beta & & =90 \% \\
g & & =5 \% \\
c & & =30 \% \\
\alpha & & =70 \%
\end{aligned}
$$

Besar garansi dari premi awal $(\beta)$, suku bunga garansi $(g)$, suku bunga cap (c) ditentukan berdasarkan hukum forfeitur. Berdasarkan Tabel Mortalita Indonesia Pria III tahun 2011 yang dapat dilihat pada lampiran batas umur seseorang adalah 111 tahun. Pada penelitian ini tertangung berusia 45 tahun, sehingga dari selisih usia tertangung dengan batas umur pada tabel mortalitas diperoleh jangka waktu kontrak tertanggung $(k)=66$ tahun. Substitusikan nilai-nilai pada deskripsi diatas pada persamaan (10) sehingga diperoleh:

$$
\begin{aligned}
& P=S_{0} \sum_{k=1}^{\infty} \Pi(k) U(k) \\
& =14,19756 \times 24.675 \\
& =R p 350.324,-
\end{aligned}
$$

\section{KESIMPULAN}

Rumus premi tunggal bersih asuransi jiwa seumur hidup unit link dengan garansi minimum dan nilai cap menggunakan metode point-to-point sebagai berikut:

$$
\begin{aligned}
P & =\sum_{k=1}^{\infty} U(k) e^{-r k}\left[\beta(1+g)^{k}\right. \\
& -\left\{\beta(1+g)^{k}-(1-\alpha)\right\} \Phi(\xi) \\
& \left.+\left\{(1+c)^{k}-(1-\alpha)\right\} \Phi(v)\right] \\
& +\alpha(\Phi(\delta)-\Phi(\kappa))
\end{aligned}
$$

dengan $\Phi$ merupakan fungsi distribusi kumulatif normal standar,

$$
\begin{aligned}
& U(k)={ }_{k-1} p_{x} q_{x+k-1}, \quad k=1,2, \ldots \\
& \delta=\sigma \sqrt{k}+\frac{\left(r-\frac{1}{2} \sigma^{2}\right) k}{\sigma \sqrt{k}} \\
& \frac{-\ln \frac{\beta(1+g)^{k}-(1-\alpha)}{\alpha}}{\sigma \sqrt{k}} \\
& \xi=\delta-\sigma \sqrt{k}
\end{aligned}
$$

$$
\begin{aligned}
& \kappa= \sigma \sqrt{k}+\frac{\left(r-\frac{1}{2} \sigma^{2}\right) k}{\sigma \sqrt{k}} \\
& \frac{-\ln \frac{(1+c)^{k}-(1-\alpha)}{\alpha}}{\sigma \sqrt{k}} \\
& v=\kappa-\sigma \sqrt{k}
\end{aligned}
$$

Berdasarkan rumus premi tunggal bersih asuransi jiwa seumur hidup unit link dengan garansi minimum dan nilai cap menggunakan metode point-to-point diperoleh premi tunggal untuk tertanggung berusia 45 tahun yang berinvestasi pada saham PT. Astra Agro Lestari,Tbk tahun 2015 sebesar $R p$ 350.324,-. Hasil perhitungan ini dapat memberikan gambaran kepada calon tertanggung besarnya premi yang harus dibayarkan apabila ingin mengikuti asuransi jiwa seumurhidup unit link.

Pada penelitian ini pembayaran manfaat dilakukan pada akhir tahun kematian tertanggung (waktu diskrit), sehingga diperlukan pembahasan lebih lanjut untuk pembayaran manfaat pada saat kematian tertanggung (waktu kontinu).

\section{DAFTAR PUSTAKA}

Bowers, N. L., Gerber, H. U., Hickman, J. C., Jones, D. A., \& Nesbitt, C. J. (1997). Actuarial Mathematics. Scaumburg, Illinois: The Society of Actuaries.

Dickson, D. C., Hardy, M. R., \& Waters, H. R. (2009). Actuarial Mathematics for Life Contingent Risks. New York: Cambridge University Press.

Elliott, R. J., \& Kopp, P. E. (2005). Mathematics of Financial Market Second Edition. New York: Springer.

Gaillardetz, P., \& Lakhmiri, J. Y. (2011). A New Premium Principle for Equity-Indexed Annuities. The Journal of Risk and Insurance, vol.78, no.1, pp. 245-265.

Hardy, M. (2003). Investment Guarantees Modeling and Risk Management for Equity-Linked Life Insurance. New Jersey: Jhon Wiley \& Sons, Inc. 
Husnan, S. (2015). Dasar-dasar Teori Portofolio dan Analisis Sekuritas Edisi Kelima. Yogyakarta: UUP STIM YKPM.

Karvof, A. (2010). Kaya Dengan Cepil. Jakarta: PT. Elex Media Komputindo.

Muyasarah, S. (2010). Analisi SWOT Terhadap Produk Asuransi Unit Link (Studi Pada PT. ASURANSI TAKAFUL KELUARGA). Skripsi. Jakarta: Universitas Islam Negeri Syarif Hidayatullah.

Sartika, M., \& Adinugraha, H. H. (2013). Konsep dan Implementasi Pengelolaan Dana Premi Unit Link Syari'ah. Jurnal Asuransi dan Manajemen Resiko, vol.1, no.2, pp. 22-38.
Sembiring, R. K. (1986). Buku Materi Pokok Asuransi 1. Jakarta: Universitas Terbuka.

Tandelilin, M. C. (2010). Portofolio dan Investasi Teori dan Aplikasi. Yogyakarta: Kanisius ( Anggota IKAPI).

Yahoo Finance, http://finance.yahoo.com/ quote/AALI.JK/. Diakses: 13 Mei 2016

Tabel Mortalita Indonesia III Pria, http://www.academia.edu/6526816/Tabel_ Mortalita_2011. Diakses: 13 Mei 2016

BI Rate, http://www.bi.go.id/en/moneter/birate/data/Default.aspx.

Diakses:

November

2016 